\title{
Should Iliac Wing Screws Be Included in Long Segment Dynamic Stabilization?
}

Ali Fahir Özer ${ }^{1}$, Ahmet Levent Aydın ${ }^{1}$, Mehdi Hekimoğlu ${ }^{2}$, Önder Çerezci ${ }^{3}$, Ahmet T. Başak ${ }^{2}$, Ozkan Ates $^{1}$, Tunc Oktenoglu ${ }^{1}$, Mehdi Sasani ${ }^{1}$

1. Neurosurgery, Koç University School of Medicine, Istanbul, TUR 2. Neurosurgery, American Hospital, Istanbul, TUR

3. Physical Treatment and Rehabilitation, American Hospital, Istanbul, TUR

Corresponding author: Ali Fahir Özer, alifahirozer@gmail.com

\section{Abstract}

\section{Background}

In this article, clinical satisfaction and radiological results are discussed in a series of patients where the iliac wings participate in dynamic stabilization. Dynamic stabilization is an effective alternative surgical treatment method, especially in clinical pictures that go with pain due to minor instabilities. Practically the unique surgical instrument used in multilevel instabilities is the Dynesys system. The most important drawback of the Dynesys system is that the $\mathrm{S} 1$ screws become loose in time. In this article, our aim is to find solution to $\mathrm{S} 1$ insufficiency by extension of the system to the iliac wings.

\section{Methods}

Nineteen patients (eight females, 11 males) with a mean age of 54.16 were included in the study. Patients had multilevel (level 2 and above) instability, iliac wings were included in the stabilized segments, and Visual Analog Scale (VAS) and Oswestry Disability Index (ODI) were used for patient follow-up.

\section{Results}

First year results showed a significant improvement in VAS and ODI. Regarding the complications, infection developed in one patient, loosening in the proximal iliac wing in one patient, and both S1 and iliac proximals in one patient, but no clinical findings were encountered.

\section{Conclusion}

When more than two levels of dynamic systems are used in chronic instability, especially in the elderly patients, S1 screws are loosened. In these patients, if the iliac bones are also included in stabilization, this problem is solved successfully. However unfortunately, Dynesys system does not have a screw suitable for the iliac bones.

Review began 01/27/2021 Review ended 02/16/2021 Published 02/24/2021

\section{() Copyright 2021}

Özer et al. This is an open access article distributed under the terms of the Creative Commons Attribution License CC-BY 4.0., which permits unrestricted use, distribution, and reproduction in any medium, provided the original author and source are credited.
Categories: Neurosurgery

Keywords: dynesys system, multilevel instability, iliac wing screwing

\section{Introduction}

The concept of dynamic stabilization was defined by Graf in 1991 as an alternative to rigid fixation and fusion surgery in chronic instabilities [1]. The system was later developed by Stoll and Dubois as a Dynesys system and continued to be used thereafter [2]. These systems are based on the principle that the screw is rigid and the rod is dynamic. The spine can perform its physiological movements in all directions in a limited range, to the extent permitted by the dynamic rod.

The next development in dynamic systems was carried out by Von Strempel [3,4]. In this system, the screw head is dynamic and the rod is rigid. Since the rod is rigid, there is a serious limitation in the forward, lateral bending and rotational movements of the spine even at one level. For this reason, it is recommended to use at most for two levels. Hardware complication rates are high in long-term use, even at two levels [5].

These two systems were used together by Kaner et al. [6]. The most physiological results were obtained, matching the movement of a motion segment, and single level complication rates were significantly reduced. Patient satisfaction was reasonable [6-10]. However, this system was not suitable for multilevel use even in this form. A dynamic rod or new design that fits the long level was required. Therefore, the Modular Orthrus System has been developed and is still under development [11-13].

After the Dynesys system, Orthrus system was used in long segment stabilization and multilevel instabilities yielding successful results. Its advantage is to let revision of just the problematic segment instead of the whole system, since it is modular. 
However, when you include sacrum to stabilization in long segment stabilizations, although the upper segment is dynamic, the S1 screw is likely to loosen since the whole system is semirigid. For this reason, the biomechanical rules for rigid systems are valid here in dynamic stabilization, and the iliac wings should also be included in dynamic stabilization. In this article, clinical satisfaction and radiological results are discussed in a series of patients where the iliac wings participate in dynamic stabilization.

\section{Materials And Methods}

This study includes 19 patients who had multilevel stabilization (eight female, 11 male), the average age is 54.1. Deformity patients without any coronal or sagittal imbalance, patients with multilevel instability due to previous surgery or progressive develop degenerative disc disease, and loosened S1 screw due to osteoporosis were included in the study. The diagnosis, accompanying neurological findings, bone scan results and stabilization levels of the patients are given in Table 1. Dynesys system (Zimmer Spine, Warsaw, IN) was used for all patients. Preoperative and postoperative four-month and one-year clinical and radiological controls of the patients were conducted. Visual analog scale (VAS) and Oswestry scales were used for clinical controls. Radiologically, bone scan, A-P spine radiographs, lumbar CT and MRI were performed for all patients before surgery, and the same examinations were repeated at the 4 th month and 1 st year controls.

\begin{tabular}{|c|c|c|c|c|c|c|c|c|}
\hline & Age & Gender & Previous operation & Complaint & $\begin{array}{l}\text { Neurological } \\
\text { findings }\end{array}$ & Diagnosis & $\begin{array}{l}\text { Discectomy and } \\
\text { instrumentation level }\end{array}$ & $\begin{array}{l}\text { T- } \\
\text { score }\end{array}$ \\
\hline 1 & 63 & M & None & $\begin{array}{l}\text { Lumbalgia } \\
\text { right } \\
\text { sciatalgia }\end{array}$ & $\begin{array}{l}\text { Right } L 5 \\
\text { radiculopathy }\end{array}$ & L5-S1 HNP* & L5-S1 discectomy, L3-IW** & 2.5 \\
\hline 2 & 50 & M & L4-5 discectomy & $\begin{array}{l}\text { Left } \\
\text { sciatalgia }\end{array}$ & $\begin{array}{l}\text { Right L3-4-5 } \\
\text { radiculopathy }\end{array}$ & $\begin{array}{l}\text { L2-3, L4-5, L5-S1 } \\
\text { HNP }\end{array}$ & L5-S1 discectomy, L2-IW & 1.8 \\
\hline 3 & 47 & $\mathrm{M}$ & None & $\begin{array}{l}\text { Lumbalgia } \\
\text { left sciatalgia }\end{array}$ & $\begin{array}{l}\text { Left L5 } \\
\text { radiculopathy }\end{array}$ & L5-S1 HNP & L5-S1 discectomy, T12-IW & 1.7 \\
\hline 4 & 55 & $\mathrm{~F}$ & L5-S1 discectomy & Lumbalgia & Normal & DDD & L3-IW & 3 \\
\hline 5 & 41 & $\mathrm{~F}$ & None & $\begin{array}{l}\text { Lumbalgia } \\
\text { left sciatalgia }\end{array}$ & Normal & L2-S1 DDD & L2-IW & 2 \\
\hline 6 & 58 & M & L4-5 discectomy & $\begin{array}{l}\text { Lumbalgia } \\
\text { right } \\
\text { sciatalgia }\end{array}$ & Right Achilles - & $\begin{array}{l}\text { L3-4 deg. } \\
\text { Spondylolisthesis, } \\
\text { L4-5 recurrence }\end{array}$ & L4-5 discectomy, L3-IW & 2.2 \\
\hline 7 & 33 & $\mathrm{~F}$ & None & $\begin{array}{l}\text { Lumbalgia } \\
\text { left sciatalgia }\end{array}$ & $\begin{array}{l}\text { Motor loss in } \\
\text { the left foot }\end{array}$ & $\begin{array}{l}\text { L4-5 HNP, L3-4, L5- } \\
\text { S1 DDD }\end{array}$ & L4-5 discectomy, L3-IW & 3 \\
\hline 8 & 64 & M & None & Lumbalgia & $\begin{array}{l}\text { Right Laseque } \\
45\end{array}$ & S1 screw loosening & $\begin{array}{l}\text { L3-4 L4-5 decompression, } \\
\text { L3-IW }\end{array}$ & 2 \\
\hline 9 & 58 & M & T11-S1 IW stabilization & $\begin{array}{l}\text { Lumbar and } \\
\text { bilateral leg } \\
\text { pain }\end{array}$ & None & S1 screw loosening & T11-IW & 2.5 \\
\hline 10 & 69 & $\mathbf{F}$ & Previous operation twice & Lumbalgia & None & $\begin{array}{l}\text { DDD from L1-2 to L5- } \\
\text { S1 }\end{array}$ & T12-IW & 3 \\
\hline 11 & 48 & $\mathrm{~F}$ & $\begin{array}{l}\text { L4-5 discectomy and } \\
\text { dynamic stabilization }\end{array}$ & $\begin{array}{l}\text { Lumbalgia } \\
\text { left sciatalgia }\end{array}$ & $\begin{array}{l}\text { Left laseque } \\
45, \text { Left } \\
\text { Achilles - }\end{array}$ & L5-S1 HNP & L4-IW & 2.5 \\
\hline 12 & 60 & M & $\begin{array}{l}\text { L5-S1 discectomy and } \\
\text { dynamic stabilization }\end{array}$ & $\begin{array}{l}\text { Lumbalgia } \\
\text { right } \\
\text { sciatalgia }\end{array}$ & None & $\begin{array}{l}\text { L5-S1 recurrence S1 } \\
\text { screw loosening }\end{array}$ & L5-S1 discectomy, L5-IW & 2 \\
\hline 13 & 51 & M & None & $\begin{array}{l}\text { Lumbalgia } \\
\text { right } \\
\text { sciatalgia }\end{array}$ & None & DDD, L3-4 HNP & L3-4 discectomy, L1-IW & 2.2 \\
\hline 14 & 50 & $\mathrm{~F}$ & None & $\begin{array}{l}\text { Lumbalgia } \\
\text { right } \\
\text { sciatalgia }\end{array}$ & $\begin{array}{l}\text { Right laseque } \\
30\end{array}$ & $\begin{array}{l}\text { L5-S1 HNP, L4-5 } \\
\text { DDD }\end{array}$ & L5-S1 discectomy, L4-IW & 2.5 \\
\hline 15 & 64 & $\mathrm{~F}$ & None & Lumbalgia & Left femoral & T12-S1 DDD Listh & 4-5 discectomy, T10-IW & 3.2 \\
\hline
\end{tabular}




\section{Cureus}

\begin{tabular}{|c|c|c|c|c|c|c|c|c|}
\hline & & & & left sciatalgia & stretch test + & at L2-3, L4-5 & & \\
\hline 16 & 59 & M & $\begin{array}{l}\text { Instrumented before } \\
\text { (spinal stenosis) }\end{array}$ & Claudication & $\begin{array}{l}\text { Right EHL 3/5, } \\
\text { Bilateral } \\
\text { Achilles - }\end{array}$ & $\begin{array}{l}\text { Lumbar spinal } \\
\text { stenosis, extensive } \\
\text { DDD }\end{array}$ & $\begin{array}{l}\text { Decompression, Bilateral L4, } \\
\text { L5-S1 foraminotomy, L1-IWW }\end{array}$ & 2.5 \\
\hline 17 & 64 & M & Discectomy & $\begin{array}{l}\text { Right } \\
\text { sciatalgia }\end{array}$ & $\begin{array}{l}\text { Right laseque } \\
20\end{array}$ & $\begin{array}{l}\text { L3-4, L4-5, L5-S1 } \\
\text { spinal stenosis }\end{array}$ & $\begin{array}{l}\text { L3-4 unilateral } \\
\text { decompression, L4-5, L5-S1 } \\
\text { discectomy, L3-IW }\end{array}$ & 2.2 \\
\hline 18 & 51 & $\mathrm{~F}$ & None & Lumbalgia & Normal & $\begin{array}{l}\text { L2-3, L3-4, L4-5, L5- } \\
\text { S1 DDD }\end{array}$ & L2-IW & 2.6 \\
\hline 19 & 44 & M & $\begin{array}{l}\text { L4-5 decompression } \\
\text { and L2-5 dynamic } \\
\text { stabilization }\end{array}$ & Lumbalgia & Normal & $\begin{array}{l}\text { L2-3, L3-4, L4-5, L5- } \\
\text { S1 DDD }\end{array}$ & L2-IW & 1.5 \\
\hline
\end{tabular}

TABLE 1: The diagnosis, accompanying neurological findings, bone scan results and stabilization levels of the patients

\section{Surgical intervention}

Decompressive surgery was performed initially in patients with lumbar disc herniation, foraminal or central canal stenosis leading to neurological deficits. Then, after installing transpedicular screws at the previously determined levels, the rod system was tightened and fixed to the screws. Afterwards, the spacers were inserted between the screws (Figure 1). Postoperative flatback deformity was tried to be prevented by giving hyperextension position to the lumbar region of the operating table before inserting the rods.
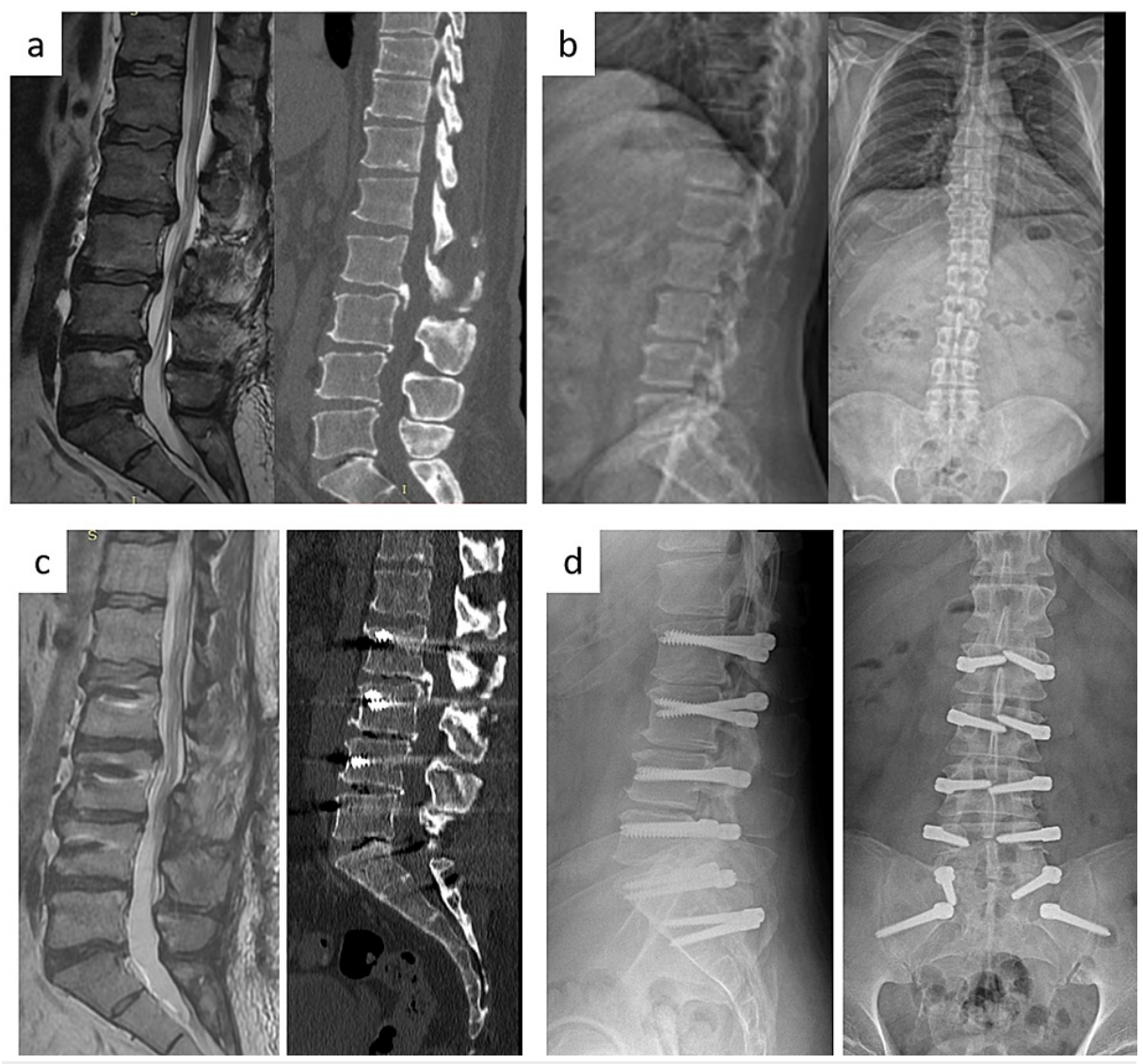

\section{FIGURE 1: Patient sample}

a) T2-weighted MR image and CT scan show severe degenerative disc disease in L2-3, L3-4, L4-5 and L5-S1 levels. b) Direct X-ray shows decreased disc height, osteophytes and flat back deformity but no apparent balance problem. c) T2-weighted MR image shows repeated posterior annuluses in every level via microsurgical way and CT scan lateral view shows stabilisation with dynamic system including iliac wings. d) Anterior-posterior (AP) and lateral X-ray. 


\section{Results}

There was no change in sagittal and coronal balance in preoperative and postoperative direct X-ray examinations. CT and MR examinations performed on the 4th month and one year after the operation. Four-month CT and MR examinations did not reveal any problems with the screws. In the sense of complications, infection developed in one patient, loosening of the iliac wing screw in one patient, and both S1 and iliac proximals in one patient. Infection was detected at one year control CT and MR examinations.

In infected patients iliac screw and rods were removed. After three months of antibiotic treatment, the iliac screw was reinserted and the rods were inserted to the entire system. No loosening was seen in the follow-up controls.

In patient with proximal screw loosening no symptoms were seen. Apart from this infected patient, a significant improvement was found in life quality scales.

VAS and ODI results of the patients, including these two patients, improved greatly (Table 2). Mean preoperative VAS was 7.16 , 4th month postoperative VAS was 3.11 and 12 th month postoperative VAS was 1.55 .

\begin{tabular}{|c|c|c|c|c|c|c|}
\hline & Preop VAS & 4-month VAS & 12-month VAS & Preop ODI & 4-month ODI & 12-month ODI \\
\hline 1 & 7.00 & 4.00 & 2.00 & 58.00 & 36.00 & 24.00 \\
\hline 2 & 7.00 & 3.00 & 1.00 & 58.00 & 38.00 & 18.00 \\
\hline 3 & 8.00 & 3.00 & 1.00 & 68.00 & 36.00 & 24.00 \\
\hline 4 & 6.00 & 2.00 & 0.00 & 64.00 & 12.00 & 12.00 \\
\hline 5 & 6.00 & 4.00 & 2.00 & 64.00 & 24.00 & 16.00 \\
\hline 6 & 7.00 & 3.00 & 2.00 & 62.00 & 26.00 & 16.00 \\
\hline 7 & 8.00 & 4.00 & 2.00 & 92.00 & 38.00 & 12.00 \\
\hline 8 & 7.00 & 2.00 & 2.00 & 70.00 & 26.00 & 16.00 \\
\hline 9 & 8.00 & 4.00 & 1.00 & 62.00 & 18.00 & 12.00 \\
\hline 10 & 7.00 & 5.00 & 4.00 & 70.00 & 52.00 & 36.00 \\
\hline 11 & 8.00 & 4.00 & 2.00 & 80.00 & 12.00 & 6.00 \\
\hline 12 & 7.00 & 3.00 & 1.00 & 64.00 & 36.00 & 12.00 \\
\hline 13 & 7.00 & 3.00 & 2.00 & 56.00 & 18.00 & 16.00 \\
\hline 14 & 8.00 & 2.00 & 0.00 & 80.00 & 16.00 & 12.00 \\
\hline 15 & 6.00 & 2.00 & 2.00 & 62.00 & 26.00 & 12.00 \\
\hline 16 & 8.00 & 2.00 & 1.00 & 56.00 & 18.00 & 8.00 \\
\hline 17 & 7.00 & 3.00 & 1.00 & 72.00 & 18.00 & 16.00 \\
\hline 18 & 7.00 & 3.00 & 2.00 & 68.00 & 42.00 & 24.00 \\
\hline 19 & 8.00 & 3.00 & 2.00 & 56.00 & 32.00 & 16.00 \\
\hline Mean & 7.16 & 3.11 & 1.55 & 67.00 & 27.33 & 16.22 \\
\hline
\end{tabular}

\section{TABLE 2: VAS and ODI results of the patients}

VAS: Visual Analog Scale; ODI: Oswestry Disability Index.

Concerning the ODI scores, preoperative ODI score was 67.00, postop four-month ODI score was 27.33 and 12-month postoperative ODI score was 16.22. 


\section{Discussion}

One of the most important points of success in spine surgery lies in the detection of instability before surgery or presumption of postsurgical instability. For surgical success, a good balance between decompression and stabilization must be established. Another important point is to choose the most appropriate method for the benefit of the patient.

There are dozens of articles in the literature that show that the dynamic system is an effective treatment modality for chronic instabilities [14-19]. We think the same.

Di Silvestre used the dynamic system for the first time in multilevel instabilities and reported successful results. Since osteotomy may be required in patients with sagittal and coronal imbalance, dynamic systems are not suitable. However, we believe that it is not correct to perform fusion surgery persistently for deformity patients who do not have balance problems. Dynamic systems can be used easily for this group of patients. Although Di Silvestre does not mention S1 screw failure in his articles, in our own experience, we observed that the possibility of loosening of the $\mathrm{S} 1$ screws increases when the dynamic system extends two levels above. This problem also existed in fusion surgery. For this reason, it was tried to be solved by installing an anterior support and extension to the iliac wings. Age and associated osteoporosis are of great importance in screw loosening. However, even if the bone density is acceptable, loosening is still possible, especially for $\mathrm{S} 1$ screws. When the literature is reviewed, similar complaints are reported for dynamic systems $[20,21]$.

In spinopelvic fixation, either anterior column support, anterior lumbar interbody fusion (ALIF) or posterior lumbar interbody fusion (PLIF) is required to prevent loosening of the S1 screw. Another technique is descending to the iliac crest [22]. Since we have no chance of interbody fusion in dynamic systems, we decided to put screws on the iliac wings so that the S1 screws do not loosen.

As it is known, the lumbosacral region is under the effect of shear forces, which are $100 \mathrm{~N}$, during bending [23]. McCord et al. developed the concept of "pivot point" for this region for the first time biomechanically [24]. They determined the pivot point as the point where the central axis of the middle osteoligamentous column intersects the line between the last lumbar vertebra and the sacrum. Another important concept in sacral fixation is the three-zone theory defined by O'Brien [25]. Zone I is the vertebral body of S1, which includes the cephalate sacral ala. Zone II includes the bony structure of the caudal sacral ala, the vertebral body of S2, extending to the coccyx, and Zone III is the iliac bones. As the fixation becomes caudal, the ability of fixation to maintain stability increases. Therefore, Zone III is important in terms of stabilization and the resistance against pull out increases in the stabilizations made in this zone. In zone III, the fixation point with the screw placed in the ileum remains in front of the lumbosacral pivot point and increases the stability of the construction. For this reason, iliac screws are designed as long screws to pass the pivot point. However, since no screws of this length are designed in the current Dynesys system, we tried to achieve a stabilization equal to the stabilization provided by Zone I, at least with a screw slightly longer than the length of the S1 screw, using the longest screw in hand. When we evaluate the results, we will be able to say that we have been successful. However, we think that, longer screws would lead to better results.

It should not be forgotten that the condition of the muscles, body mass index and bone density also play an important role in screw loosening in fusion surgery. However, another similar important factor is fusion at three or more levels [26]. Because, as the fusion level increases, the lever arm will extend, and the extended lever arm, which includes the upper lumbar vertebrae during bending at the lumbosacral pivot point, will put excessive load on the S1 screw and will cause loosening. Because of their dynamic properties, we can think that $\mathrm{S} 1$ and iliac screws do not have to be loaded as much as rigid screws. However, since it shares the load transfer, it continues to carry load in the anterior column regularly. In this case, even if S1 and iliac screws do not take as much load as in rigid systems, but still they continue to take load continuously. It is a fact that, these systems are semirigid systems. Since the iliac screws are consecutive screw system after S1, they should also play an important role in reducing the load on S1. From this point of view, placing two screws on the iliac wings can create a biomechanically strong construction. When the load distribution is balanced in the long segment, it is very advantageous compared to the short segment and the complication rates are reduced [27].

It should not be forgotten that the Dynesys system is currently used for long segments in the market and there is no alternative. The Dynesys system is a semirigid system. It is more rigid than the physiological motion segment of the spine. For this reason, it is called semirigid. In systems combining dynamic screws and dynamic rods which mimic the motion segment mechanics, the stress on the S1 screw will be less $[8,9]$. However, even if this goal is achieved, we strongly believe that the iliac screws are still necessary biomechanically.

\section{Conclusions}

As a result, inserting screws into the iliac wings without compromising the basic concepts in multilevel spine stabilization, as in rigid fixation, will significantly reduce the loosening of S1 screws. We believe that stabilization systems including more dynamic systems in the future will be for the benefit of screw loosening 
problems.

\section{Additional Information \\ Disclosures}

Human subjects: Consent was obtained or waived by all participants in this study. Animal subjects: All authors have confirmed that this study did not involve animal subjects or tissue. Conflicts of interest: In compliance with the ICMJE uniform disclosure form, all authors declare the following: Payment/services info: All authors have declared that no financial support was received from any organization for the submitted work. Financial relationships: All authors have declared that they have no financial relationships at present or within the previous three years with any organizations that might have an interest in the submitted work. Other relationships: All authors have declared that there are no other relationships or activities that could appear to have influenced the submitted work.

\section{References}

1. Graf H: Lumbar instability; surgical treatment without fusion. Rachis. 1992, 412:123-137.

2. Stoll TM, Dubois G, Schwarzenbach O: The dynamic neutralization system for the spine: a multi-center study of a novel non-fusion system. Eur Spine J. 2002, 11:170-178. 10.1007/s00586-002-0438-2

3. Strempel AV, Moosmann D, Stoss C, Martin A: Stabilisation of the degenerated lumbar spine in the nonfusion technique with cosmic posterior dynamic system. WSJ. 2006, 1:40-47.

4. Strempel AV: Dynamic stabilisation: cosmic system. Interact Surg. 2008, 3:229-236. 10.1007/s11610-0070044-4

5. Ciplak NM, Suzer T, Senturk S, et al.: Complications of 2-level dynamic stabilization: a correlative clinical and radiological analysis at two-year follow-up on 103 patients. Turk Neurosurg. 2018, 28:756-762. 10.5137/1019-5149.JTN.21036-17.1

6. Kaner T, Sasani M, Oktenoglu T, Cosar M, Ozer AF: Utilizing dynamic rods with dynamic screws in the surgical treatment of chronic instability: a prospective clinical study. Turk Neurosurg. 2009, 19:319-326.

7. Ozer AF, Oktenoglu T, Egemen E, et al.: Lumbar single-level dynamic stabilization with semi-rigid and full dynamic systems: a retrospective clinical and radiological analysis of 71 patients. Clin Orthop Surg. 2017, 9:310-316. 10.4055/cios.2017.9.3.310

8. Erbulut DU, Kiapour A, Oktenoglu T, Ozer AF, Goel VK: A computational biomechanical investigation of posterior dynamic instrumentation: combination of dynamic rod and hinged (dynamic) screw. J Biomech Eng. 2014, 136:051007. 10.1115/1.4027060

9. Oktenoglu T, Erbulut DU, Kiapour A, et al.: Pedicle screw-based posterior dynamic stabilisation of the lumbar spine: in vitro cadaver investigation and a finite element study. Comput Methods Biomech Biomed Engin. 2015, 18:1252-1261. 10.1080/10255842.2014.890187

10. Kaner T, Sasani M, Oktenoglu T, Aydin AL, Ozer AF: Minimum two-year follow-up of cases with recurrent disc herniation treated with microdiscectomy and posterior dynamic transpedicular stabilisation. Open Orthop J. 2010, 4:120-125. 10.2174/1874325001004010120

11. Ozer AF, Cevik OM, Erbulut DU, et al.: A novel modular dynamic stabilization system for the treatment of degenerative spinal pathologies. Turk Neurosurg. 2019, 29:115-120. 10.5137/1019-5149.JTN.23227-18.1

12. Di Silvestre M, Lolli F, Bakaloudis G: Degenerative lumbar scoliosis in elderly patients: dynamic stabilization without fusion versus posterior instrumented fusion. Spine J. 2014, 14:1-10. 10.1016/j.spinee.2012.10.023

13. Di Silvestre M, Lolli F, Greggi T, Vommaro F, Baioni A: Adult's degenerative scoliosis: midterm results of dynamic stabilization without fusion in elderly patients - Is it effective?. Adv Orthop. 2013, 2013:365059. $10.1155 / 2013 / 365059$

14. Guigui P, Ferrero E: Surgical treatment of degenerative spondylolisthesis. Orthop Traumatol Surg Res. 2017, 103:11-20. 10.1016/j.otsr.2016.06.022

15. Hoppe S, Schwarzenbach O, Aghayev E, Bonel H, Berlemann U: Long-term outcome after monosegmental L4/5 stabilization for degenerative spondylolisthesis with the Dynesys device. Clin Spine Surg. 2016, 29:7277. 10.1097/BSD.0b013e318277ca7a

16. Lee CH, Jahng TA, Hyun SJ, et al.: Dynamic stabilization using the Dynesys system versus posterior lumbar interbody fusion for the treatment of degenerative lumbar spinal disease: a clinical and radiological outcomes-based meta-analysis. Neurosurg Focus. 2016, 40:7. 10.3171/2015.10.FOCUS15426

17. Kuo CH, Chang PY, Wu JC, et al.: Dynamic stabilization for L4-5 spondylolisthesis: comparison with minimally invasive transforaminal lumbar interbody fusion with more than 2 years of follow-up. Neurosurg Focus. 2016, 40:3. 10.3171/2015.10.FOCUS15441

18. Gille O, Challier V, Parent H, et al.: Degenerative lumbar spondylolisthesis. Cohort of 670 patients, and proposal of a new classification. Orthop Traumatol Surg Res. 2014, 100:311-315. 10.1016/j.otsr.2014.07.006

19. Kaner T, Dalbayrak S, Oktenoglu T, Sasani M, Aydin AL, Ozer AF: Comparison of posterior dynamic and posterior rigid transpedicular stabilization with fusion to treat degenerative spondylolisthesis. Orthopedics. 2010, 33:309. 10.3928/01477447-20100329-09

20. Kuo CH, Chang PY, Tu TH, et al.: The effect of lumbar lordosis on screw loosening in Dynesys dynamic stabilization: four-year follow-up with computed tomography. Biomed Res Int. 2015, 2015:152435. $10.1155 / 2015 / 152435$

21. Ko CC, Tsai HW, Huang WC, et al.: Screw loosening in the Dynesys stabilization system: radiographic evidence and effect on outcomes. Neurosurg Focus. 2010, 28:10. 10.3171/2010.3.FOCUS1052

22. Fleischer GD, Kim YJ, Ferrara LA, Freeman AL, Boachie-Adjei O: Biomechanical analysis of sacral screw strain and range of motion in long posterior spinal fixation constructs: effects of lumbosacral fixation strategies in reducing sacral screw strains. Spine (Phila Pa 1976). 2012, 37:163-169. 


\section{Cureus}

10.1097/BRS.0b013e31822ce9a7

23. Kornblatt MD, Casey MP, Jacobs RR: Internal fixation in lumbosacral spine fusion. A biomechanical and clinical study. Clin Orthop Relat Res. 1986, 203:141-150.

24. McCord DH, Cunningham BW, Shono Y, Myers JJ, McAfee PC: Biomechanical analysis of lumbosacral fixation. Spine (Phila Pa 1976). 1992, 17:235-243. 10.1097/00007632-199208001-00004

25. O’Brien MF: Sacropelvic fixation in spinal deformity. In: Spinal Deformities: The Comprehensive Text. DeWald RL (ed): Thieme, New York; 2003. 601-614.

26. Kim JB, Park SW, Lee YS, Nam TK, Park YS, Kim YB: The effects of spinopelvic parameters and paraspinal muscle degeneration on S1 screw loosening. J Korean Neurosurg Soc. 2015, 58:357-362. 10.3340/jkns.2015.58.4.357

27. Wu Y, Chen CH, Tsuang FY, Lin YC, Chiang CJ, Kuo YJ: The stability of long-segment and short-segment fixation for treating severe burst fractures at the thoracolumbar junction in osteoporotic bone: a finite element analysis. PLoS ONE. 2019, 14:0211676. 10.1371/journal.pone.0211676 